\title{
Bats (Plecotus auritus) use contact calls for communication among roost mates
}

\author{
Joanna Furmankiewicz ${ }^{1}$ (D) Gareth Jones ${ }^{2}$
}

Received: 13 March 2021 / Accepted: 10 October 2021 / Published online: 28 October 2021

(c) The Author(s) 2021

\begin{abstract}
Communication between group members is mediated by a diverse range of signals. Contact calls are produced by many species of birds and mammals to maintain group cohesion and associations among individuals. Contact calls in bats are typically relatively low-frequency social calls, produced only for communication. However, echolocation calls (higher in frequency and used primarily for orientation and prey detection) can also facilitate interaction among individuals and location of conspecifics in the roost. We studied calling behaviour of brown long-eared bats (Plecotus auritus) during return to maternity roosts in response to playbacks of social and echolocation calls. We hypothesised that calling by conspecifics would elicit responses in colony members. Bat responses (inspection flights and social calls production) were significantly highest during social call and echolocation call playbacks than during noise (control) playbacks. We suggest that social calling in maternity roosts of brown long-eared bat evolved to maintain associations among roostmates, rather than to find roosts or roostmates, because this species is strongly faithful to roosts and the social groups and roosts are stable over time and space. Living in a stable social group requires recognition of group members and affiliation of social bonds with group members, features that may be mediated by vocal signals.
\end{abstract}

Keywords Eavesdropping $\cdot$ Greeting behaviour $\cdot$ Affiliation $\cdot$ Social bonds $\cdot$ Social behaviour

\section{Introduction}

Many animals aggregate with conspecifics to form permanent or periodically stable groups (Krebs and Davies 2012). Group size, composition and stability may change over time and space due to changes in daily or seasonal activities (e.g. night foraging, resting in the roost, mating, migration) or because of the fission-fusion social organization of the group. Therefore, social integration of the group members during reunion plays an important role in social species (Bradbury and Vehrencamp 2011).

Handling editor: Danilo Russo.

Joanna Furmankiewicz

joanna.furmankiewicz@uwr.edu.pl

1 Department of Behavioural Ecology, Faculty of Biological Sciences, University of Wroclaw, Sienkiewicza 21, 50-335 Wrocław, Poland

2 School of Biological Sciences, University of Bristol, 24 Tyndall Avenue, Bristol BS8 1TQ, UK
Coordination of group activity and information on the location and identity of group members can be mediated by signaling. Many species of birds and mammals maintain contact by acoustic signaling, emitting separation or contact calls (Marler 2004; Kondo and Watanabe 2009; Fichtel and Manser 2010). Reunions in fission-fusion social systems also commonly involve greeting displays in some mammals and birds that facilitate recognition, expression of intention and mutual affiliation, reassurance, or assessment (Bradbury and Vehrencamp 2011).

Bats serve as a good model taxon for studying group reunion, because they are among the most gregarious of animal taxa and often form social groups with varying levels of complexity and stability (Kerth 2008; Wilkinson et al. 2019). Group living and nocturnality have led to bats using a wide range of acoustic signals for communication. There is an increasing number of studies on bats concerning the function of vocalisations in maintaining group cohesion or in locating resources including food, roosts and mates (reviewed by Fenton 2003; Altringham and Fenton 2003; Chaverri et al. 2018). 
Many bat species produce social calls as well as echolocation calls. Social calls are often lower in frequency, multiharmonic and are complex sounds that can potentially encode large amounts of information. Therefore, they are adapted for communication and are used for different interactions among individuals (Fenton 2003). For example social calls may be used for information transfer about ephemeral food patches when bats form groups at departures (Wilkinson 1992) or for coordination of foraging among group members (Wilkinson and Boughman 1998). Social calling when approaching roosts may also recruit roostmates and facilitate group formation (Vaughan and O'Shea 1976; O'Shea and Vaughan 1977; Furmankiewicz et al. 2011; Arnold and Wilkinson 2011; Chaverri et al. 2013; Gillam et al. 2013).

In contrast, echolocation is used for orientation and often for food acquisition. Nonetheless, echolocation calls can possess group, age, sex and individual signatures, which may facilitate individual recognition and interactions among group members and may be used as cues when seeking resources (review in Fenton 2003; Gillam and Fenton 2016). Some bats eavesdrop on echolocation calls of conspecifics to locate patchily distributed food or to coordinate social foraging (Barclay 1982; Balcombe and Fenton 1988; Gillam 2007; Dechmann et al. 2009; Cvikel et al. 2015). Eavesdropping on both echolocation and social calls of conspecifics may also reduce the costs of roost location, because it decreases search time (Ruczyński et al. 2007, 2009; Schöner et al. 2010; Furmankiewicz et al. 2011).

We used playback experiments to explore the role of vocal behaviour in the brown long-eared bat (Plecotus auri$t u s$ ) during arrival at day roosts by exploring the response of bats to two types of vocalisations, as individuals return to their roosting places. Brown long-eared bats form stable philopatric colonies typically numbering 10-30 adults (Heise and Schmidt 1988; Entwistle et al. 1996; Swift 1998; Burland et al. 2006; Furmankiewicz 2016). Colonies usually inhabit attics, and also occur in tree holes or bat boxes (Heise and Schmidt 1988; Fleischmann and Kerth 2014; Furmankiewicz 2016). The attic-dwelling bats are strongly faithful both to roosts and colonies (Entwistle et al. 1996; Swift 1998; Furmankiewicz 2016), whereas tree-dwelling bats switch roosts and show limited fission-fusion dynamics (Fleischmann and Kerth 2014; Zeus et al. 2017). However, it seems that forest groups are socially stable despite being highly plastic in their use of roosts as evidenced for closely related barbastelle bats (Russo et al. 2017), and because they split less frequently into groups in a comparative study of three tree-dwelling species, including brown long-eared bats (Zeus et al. 2017). Bats emit audible social calls both inside and outside roosts when departing from or arriving at the colony and during flight activity around the roosts (Ahlén 1981; Swift 1998; Furmankiewicz 2004, 2016; Murphy 2012). These social calls are broadband sweeps, and are emitted as single, double or triple calls or in series of single calls (Furmankiewicz 2004, 2016). While the production of these social calls at colony entrances is well established, the function of these calls is not known.

In our study, we asked whether (1) brown long-eared bats use social calls to maintain contact among colony members on return to the colony roosts, and (2) the bats also used echolocation calls for the same purpose, since there is a growing evidence that echolocation calls of bats are used for communication or for locating conspecifics (Dechmann et al. 2013; Gillam and Fenton 2016). Some bat species may eavesdrop on echolocation calls to locate preferred roost mates (Möhres 1967) and roosts (Ruczyński et al. 2007, 2009; Schöner et al. 2010). Social calls may be also used to find roosts or conspecifics in roosts especially in bat species that frequently switch roosts and have to update the location of new roosts or conspecifics almost every night (Furmankiewicz et al. 2011; Schöner et al. 2010; Chaverri et al. 2013). However, in bats with stable groups that are faithful to the same roosts over the season, there is no need to locate the roosts and roostmates, because of the stability of both the roost and the social group. Hence calls would play another function, such as recognition of individuals and maintenance of roosting associations among bats, as was suggested for the pallid bat Antrozous pallidus (Arnold and Wilkinson 2011).

Both functions of bat vocalisations (roost or roostmate location, and maintaining contact between individuals) may elicit call-and-respond patterns during playbacks of social stimuli. However, the motivation for bat responses would be different. Since brown long-eared bats form stable social groups, using the same roosts over the season (Entwistle et al. 2000; Furmankiewicz 2016), we hypothesised (1) that social calls emitted by brown long-eared bats have a social function and are used as contact calls among conspecifics on return to roosts after foraging. (2) Echolocation calls are less important signals or cues in interindividual interactions in brown long-eared bats, as they attenuate rapidly in the air because of their high frequencies (Lawrence and Simmons 1981; Fenton 2003; the sound attenuation was not tested here). To test these hypotheses, we designed a playback experiment consisting of two different acoustic stimuli, social and echolocation calls, and noise as a control. The playbacks were broadcasted to wild colonies of brown longeared bats, outside their roosts in south-west Poland. We predicted that bats flying back to the roost would respond by investigating the speakers more frequently and potentially by emitting more social calls in response to playbacks of social calls and echolocation calls than to the control noise. Investigation flights alone suggest that bats react to broadcasted signals and check the source of the sound, eavesdropping on conspecifics to find them or to find the roost, as shown in other bat species (Ruczyński et al. 2007, 2009; Schöner et al. 2010). However, a response with social calls 
to broadcasted signals indicates that brown long-eared bats communicate with conspecifics in the roost with social contact calls potentially involving roostmate recognition, crucial for social group stability and cooperative behavior (Krebs and Davies 2012; Ward and Webster 2016).

\section{Materials and methods}

\section{Study site}

The study was conducted in four sites in south-west Poland: three attics of churches in the villages of Bożnowice, Jabłów and Krajanów inhabited by maternity colonies (20-30 adults in each) of brown long-eared bats, and at a forest in Muszkowice, where small congeneric groups of bats (2-10 individuals) roosted in tree holes. Those groups of bats in the forest presumably form colonies that simultaneously occupy several tree cavities (Heise and Schmidt 1988). However, the total number of colonies existing in this location is unknown. The attic sites were 13-69 km apart, whereas trees with bat roosts in the forest were about $0.5-1 \mathrm{~km}$ apart.

\section{Recordings of bat calls}

Social and echolocation calls of brown long-eared bats were recorded in the attic roosts of the maternity colonies at Bożnowice, Jabłów and Krajanów during return of the bats to the roost at dawn in August and September 2007. We had no recordings from the forest in Muszkowice, because of the low number of vocalising bats and difficulties in finding their roosts. We used a condenser CM16 ultrasound microphone (frequency response $\pm 3 \mathrm{~dB}$ between 10 and $150 \mathrm{kHz}$ ) with the Avisoft UltraSoundGate 416 base unit connected to a laptop computer running Avisoft-RECORDER hardware (http://www.avisoft.com/recorder.htm) at 16-bit resolution and $250-\mathrm{kHz}$ sample rate. We assumed that we recorded most of the members of each colony, when they sequentially returned to the roosts.

\section{Preparation of playback files}

We used original sequences recorded from bats in each attic and did not delete any calls to simulate the vocal behaviour of bats returning to the roost, when several individuals fly and vocalise simultaneously. We prepared short experimental samples of both social calls and echolocation call sequences from the recordings made in each attic colony (three social and three echolocation samples). The sequence was a train of one type of social or echolocation pulses emitted one after another (Fig. 1). We only chose sequences with an optimal signal to noise ratio, where the level of signal was much higher than the background noise, resulting in a good quality recording with minimal background noise. These criteria, plus the fact that we used the longest sequences possible to increase diversity of calls, resulted in samples of different length (see below). The chosen sequences of calls came from single individuals. We assumed that the samples contained calls from different individuals, because we chose sequences from different nights and parts of the recordings, i.e. when different individuals returned to the roost. The exact number of individuals in the samples could not be assessed definitively, but it is likely that samples represented at least 12 individuals.

Social call samples were $20-75$ s long and consisted of 294-454 social calls (without echolocation calls), emitted as series of single calls or as double or triple calls (Fig. 1). The average call rate was 9.1 calls s$^{-1}$. Most of the calls contained two frequency peaks of high energy at about $14-15 \mathrm{kHz}$ and $19-20 \mathrm{kHz}$, respectively. They had minimum and maximum frequencies between 11 and $99 \mathrm{kHz}$, respectively, and up to seven harmonics. For each echolocation call sample we used from 18 to 28 echolocation call sequences between 38 and $41 \mathrm{~s}$. Each echolocation call sequence included from 7 up to 35 pulses and the average call rate was 10.3 calls s$^{-1}$. Echolocation calls had two frequency peaks of high energy: between 33 and $38 \mathrm{kHz}$ and between 60 and $70 \mathrm{kHz}$ (Fig. 1). The first peak corresponded to the first harmonic, and the second to the second harmonic. The minimum and maximum frequencies of echolocation calls were about $23 \mathrm{kHz}$ and $100-103 \mathrm{kHz}$, respectively. The pulses consisted usually of two harmonics (maximally up to three harmonics), and the maximum energy was concentrated either in the first or second harmonic (Fig. 1).

For the control we used short (about $1 \mathrm{~s}$ ) samples of background noise from the same recordings of echolocation or social calls. This way we obtained six noise samples, i.e. one sample for each attic colony and call type.

We digitally amplified all samples by $6 \mathrm{~dB}$ with 'hard limiting' the maximum amplitude to the level of the strongest signals, i.e. $-3.5 \mathrm{~dB}$ and $-4.0 \mathrm{~dB}$ for social and echolocation sounds, respectively. Hard limiting reduces gain above a given threshold of amplitude (in this case -3.5 and $-4.0 \mathrm{~dB}$ ), limiting all peaks above the threshold to the threshold level, while, maintaining the amplitude differences between loud and quiet calls. The samples from different colonies had therefore similar sound pressure levels (SPL) without overloading them and the amplitude of the broadcasted calls was fixed at a similar level as the recorded vocalisations. This procedure enabled us to preserve the original differences in amplitude between individual social or echolocation calls and thus the natural variation inherent in the bat vocalisations.

The highest amplitude of the calls and noise played back corresponded to $45-48 \mathrm{~dB}$ SPL at $1 \mathrm{~m}$ in front of the speaker. The SPL was measured in an anechoic chamber 

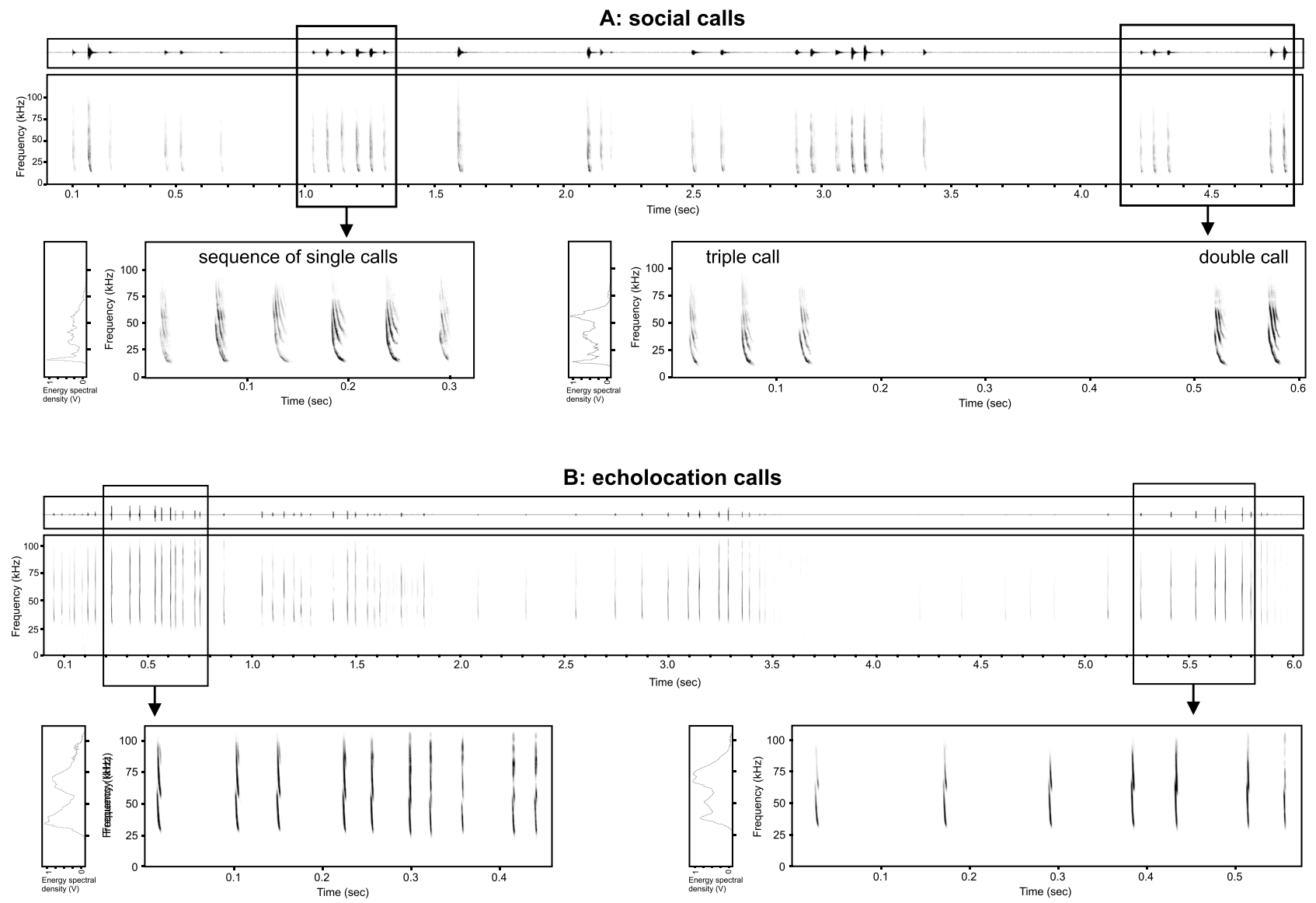

Fig. 1 Examples of social (A) and echolocation (B) call sequences broadcasted during experiments. Each panel $\mathbf{A}$ and $\mathbf{B}$ contains the amplitude envelope (at the top), spectrogram of the selected sequence

using a MK301 measurement microphone 1/4" RFT (Microtech Gefell GmbH, Gefell, Germany) and a Robotron 00,017 SPL meter (VEB Robotron Messelektronik, Dresden, Germany) with an octave filter applied.

We made three two-channel final playback files containing social (first channel) and echolocation (second channel) call samples to play back both stimuli simultaneously, because we aimed to investigate bats' choice between those two acoustic signals. For each attic colony we used one file with calls and noise recorded in the roost of the colony where experiments were conducted, because we were interested in the response of bats to familiar calls from the same colony. In the Muszkowice forest, we used the same file as for the nearest attic colony in Bożnowice (13 km distant), because we had no recordings from this site (see explanation in "Recordings of bat calls" section). We assumed that bats from the forest may be familiar with bats from the roost in Bożnowice, because at least some of the members of both colonies meet at the same underground swarming site (Furmankiewicz 2008). The response of forest bats to playback confirmed our assumption. played back (in the middle), and spectrograms with power spectra of zoomed (marked with vertical frames) sequences of calls (at the bottom)

Each channel file consisted of $20 \mathrm{~min}$ of calls (either social or echolocation) followed by $10 \mathrm{~min}$ of control noise, so each sample made of echolocation and social sequences were looped for $20 \mathrm{~min}$ and background noise for $10 \mathrm{~min}$. We did not change the order of the sequences because we assumed that the whole 20 min playback file would be presented to different individuals that come back to the roost sequentially in the morning (Furmankiewicz 2016).

We performed amplification and prepared final files for playback in Adobe Audition 1.5 software (http://www. adobe.com/products/audition.html).

\section{Playback experiments}

At each site, we performed three (at colony roosts in attics) or four playback trials (at roosts in the forest), on different nights. Altogether we conducted 13 experimental trials: nine in 2008 between 25 August and 11 September, and five in 2009 between 19 August and 11 September, when colonies consisted of adult females, males and young of the year (Entwistle et al. 2000; Furmankiewicz 2016). At each site, 
we played back the same file during all trials. To avoid pseudoreplication implications and habituation of bats to playbacks the interval between two consecutive trials within one season and one site was 12 or 15 days and 348 or 365 days at attic colonies. This was to minimize the chances of bats remembering the presented stimuli. We used shorter intervals, 1 or 8 days, in Muszkowice Forest, because consecutive trials were performed in different parts of the forest, so presumably involved different bats.

Each trial was conducted at two playback points, and consisted of two phases at each point: (1) experimental $20 \mathrm{~min}$ of test acoustic stimulus and (2) control $10 \mathrm{~min}$ of noise, so both stimuli, social calls and echolocation calls, were broadcasted simultaneously. We ran each playback trial for $30 \mathrm{~min}$, starting one hour before sunrise, i.e. when most of the colony members return to the roost (Entwistle et al. 1996; Furmankiewicz 2016). The social/echolocation calls component (experimental stimuli) of the file was twice as long as the control and the phases order was fixed because during preliminary observations we recorded delayed reaction of bats to call playbacks, i.e. responses increased after the first 10 min of playback of stimuli. As bats swarm at dawn only for about 30-40 min, we wanted to adjust our experiment to match bat activity optimally (short time window of return of most of the colony members) and to ensure enough time for bats to react. If we had played back control noise first, we would not be sure if bats do not respond to or do not notice it. We were not aware of fixed order of stimulus and control, and hence of any bias involving lower activity of bats during the control phase, because bats were arriving at the colony at a fairly consistent rate during experiments, as testified by the levels of vocal activity recorded during the control phase (see "Results" section).

We played back the social and echolocation calls simultaneously using two-channel files, so we used two sets of speakers, each set for one sound type. Each set consisted of two speakers, fixed at $180^{\circ}$ to each other to increase the sound coverage. For playbacks at attic colonies speakers were set on tripods placed on the wall surrounding the church (i.e. about $10-20 \mathrm{~m}$ from the roost), so the calls were propagated from 2.5 to $3 \mathrm{~m}$ above the ground. In the Muszkowice forest speakers were fixed on the tree trunk on a similar height, within the home ranges of bats found in 2001-2003 (Furmankiewicz 2008). The location of the speakers was changed every trial. The distance between speakers broadcasting echolocation and social stimuli was about $50 \mathrm{~m}$. We used these distances between speakers and between speakers and the roost to ensure they were close enough to the colony roost that colony members would hear the presented stimuli, but far enough that the activity at one speaker would not affect the activity of bats at another speaker. The estimated detection range of the microphone for echolocation and social calls of brown long-eared bats is less than $5 \mathrm{~m}$, and $40 \mathrm{~m}$, respectively (Ahlèn 1981; Barataud 2015). The measured intensity of our presented calls was $45-48 \mathrm{~dB}$ at $1 \mathrm{~m}$ (see above). We used a range of auditory thresholds $(-20,0,10$, and $20 \mathrm{~dB})$ of acoustic gain of the low and high frequencies for the external ear and for single neurons in brown long-eared bat (Coles et al. 1989), and the sound attenuation due to the distance and absorption in the air. Using these assumptions we calculated that the social calls will be audible at approximately $12 \mathrm{~m}$ at a detection threshold of $20 \mathrm{~dB}$ SPL, at approximately $22 \mathrm{~m}$ at a detection threshold of $10 \mathrm{~dB}$ SPL, at approximately $35 \mathrm{~m}$ at a detection threshold of $0 \mathrm{~dB}$ SPL, and at approximately $60 \mathrm{~m}$ at detection threshold of $-20 \mathrm{~dB}$. Similarly, echolocation calls will be audible at $8 \mathrm{~m}, 13 \mathrm{~m}, 18 \mathrm{~m}$, and $30 \mathrm{~m}$, respectively (calculated for $15{ }^{\circ} \mathrm{C}, 50 \%$ humidity, $1020 \mathrm{hPa}$ air pressure and open airspace). Following this, our microphones would detect only those echolocating bats that were in the audible range of one of the speakers, and echolocation calls played back from one speaker did not affect the activity of bats at the other speaker. In contrast, the social calls broadcasted from one speaker could have been audible at another speaker, and bat responses at that speaker could be recorded by the microphone at another speaker, assuming detection thresholds of $-20 \mathrm{~dB}$ and $0 \mathrm{~dB}$. However, we assumed that this overlap was negligible, because of the measures we used to analyse bat responses (see below). Responses to the stimuli (i.e. investigation flights around the speaker, see below) were only recorded at the speaker closest to the responding bat, because we assume that bat would respond towards the source of the stimuli.

We played files with a sampling rate of $250 \mathrm{kHz}$ via a Data Acquisition Card (National Instrument USB-6259 M series, National Instrument Corporation, Austin, TX, USA) using Avisoft-RECORDER (http://www.avisoft.com/recor der.htm) on a laptop connected to custom-made ultrasound amplifiers and Scan-Speak R2904 ultrasound speakers with frequency response $\pm 3 \mathrm{~dB}$ up to $160 \mathrm{kHz}$ (Scan-Speak, Videbæk, Denmark)

\section{Recordings and analysis of bat responses}

We measured vocal responses of bats using a condenser CM16 ultrasound microphone with the Avisoft UltraSoundGate416 base unit connected to a laptop computer running Avisoft-RECORDER hardware (http://www.avisoft.com/ recorder.htm).

We also observed bat flight behaviour using digital infrared video cameras (DCR-HC90E, DCR-DVD405, Sony Corporation, Tokyo, Japan) with additional external 850$\mathrm{nm}$ infrared LED illuminators (15-IL07). There was one camera with one illuminator at each playback point. The cameras were placed about $10 \mathrm{~m}$ from the speakers, directed towards it and fixed on tripods $1-1.2 \mathrm{~m}$ from the ground. The 
microphones were placed on the same tripod as the cameras about $1 \mathrm{~m}$ from the ground and directed towards the speaker.

Flight responses were classified into two categories: inspection flights (bats flying around and up to speakers) and bat passes (bats passing through the visual field of the camera and not inspecting the speakers). We were not able to identify bat species, because of the distance, speed and angle of the flying bats relative to the cameras. Hence we only included those observations in the analysis, where calls of brown long-eared bat or no echolocation were recorded during a bat's flight on video recordings, and we rejected observations containing calls of other species. Echolocation calls of brown long-eared bats are faint and only detectable when a bat is closer than about $5 \mathrm{~m}$ (Ahlén 1981; Barataud 2015), so we assumed that bats recorded by the camera and not confirmed by acoustic recordings were brown long-eared bats. There were no other bat species at our study sites that have such faint echolocation calls as those emitted by brown long-eared bats.

For analysis of recordings, we identified echolocation and social calls of brown long-eared bats (Ahlèn 1981; Barataud 1996; Furmankiewicz 2004, 2016). We measured bat calling activity using (1) the number of echolocation sequences and (2) the number of single social calls, even if such calls were emitted in double, triple or multiple series. For echolocation calls we used a sequence as a unit, because sequences are often used to measure bat activity. An echolocation call sequence was defined as containing two or more echolocation pulses, produced by a bat passing the air space sampled by the microphone, and separated from another sequence by silence (Fenton 1970; Kunz et al. 2009), that was at least three times longer than interpulse interval. The sequences of echolocation calls involved regular echolocation calls of brown long-eared bats dominated either by the first or the second harmonic or sequences of lower frequency multiharmonic calls (peak frequency $25-27 \mathrm{kHz}$ ), switching to low-frequency social calls, or with social calls interspersed in the sequence. The low-frequency and regular echolocation sequences were analysed together and all social calls were pooled together for analysis.

All sound analysis was performed by JF in SASLabPro version 4.40 (http://www.avisoft.com/soundanalysis.htm).

\section{Statistical analysis}

Statistical analysis was performed in $\mathrm{R}$ environment (ver. 3.6.3; R Core Team 2020, https://www.r-project.org/). We compared reaction of bats to playback experiments using generalised linear mixed models (GLMMs) implemented in the package "lme4" (Bates et al. 2015).

The response variables describing behaviour of bats during playback experiments-the number of passes, inspection flights, echolocation sequences and social calls-were discretized to two categories (null response $=0$, non-zero response $=1$ ) and modeled using GLMMs with binomial error and logit link. Assuming that we sampled from a general population of brown long-eared bat colonies, we fitted a random intercept for each colony to account for possible differences between them. The type of stimulus used (playback of echolocation calls v. playback of social calls) and the phase of the experiment (stimulus v. control) were fixed explanatory variables. All models included an interaction between the type of stimulus and phase of the experiment to test whether bat response differed between playback of echolocation v. playback of social calls differed, relatively to the control phase.

In the GLMM of inspection flights, the variance explained by ID of colony was estimated as zero, which produced a singular fit. We thus dropped this random term (see Bolker et al. 2009; Barr et al. 2013) and proceeded with the resulting generalised linear model (GLM). To ensure that model fits were good, we checked residual plots and proceeded with diagnostic tests using the "DHARMa" package (Hartig 2020) for GLMMs and "binomTools" (Christensen and Hansen 2014) for the GLM.

We compare bat response (inspection flights, passes, social and echolocation calls) between stimuli (social v. echolocation calls) and phases of experiment (experimental session with broadcasted calls v. control noise session). For the analysis, we used the information about bat response (null-response, non-zero response) from each phase.

We rejected results from video recordings in one trial in Jabłów from analysis because the speakers were located close to a roost of Natterer's bat (Myotis nattereri), not noted before the playback. Bats from this colony passed the visual field of the camera.

\section{Results}

Most of the bats $(87.7 \%, 128$ cases) passed the field of the camera alone, only $12.3 \%$ of all individuals were observed in pairs (8 cases). All inspection flights involved single bats.

Bat calling activity during all playback trials involved echolocation sequences and social calls of brown long-eared bat, including sequences of low frequency multiharmonic calls (peak frequency $25-27 \mathrm{kHz}$ ), switching to low frequency social calls or with social calls interspersed in the sequence. Social calls were emitted in series or as double or triple calls of single multiharmonic calls with usually two frequency peaks at around $14 \mathrm{kHz}$ and $20-25 \mathrm{kHz}$.

Response of bats varied widely across phases of the experiment and types of stimuli used in the playback (Fig. 2). The GLMMs (Table 1) revealed that bats performed more inspection flights and emitted more social calls in the playback phase than in the control phase, independently from the 


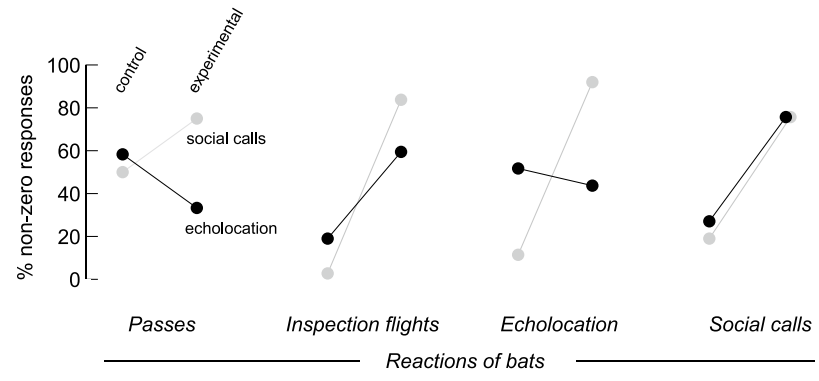

Fig. 2 Reactions of bats to playback experiments $(N=12)$ in control (noise) and experimental phase with two stimuli: social calls or echolocation calls. Behavioural responses of bats were transformed to binomial variables (observed/not observed)

type of stimulus used. In the model explaining the variation in production of echolocation sequences, there was a significant interaction between the phase of experiment and type of stimuli in the playback: bats produced more echolocation sequences when stimulated with the playback of social calls than with the playback of echolocation calls (Table 1).

\section{Discussion}

Our results support the hypothesis that social calling by brown long-eared bats when returning to maternity roosts is used to maintain contact among roost mates, and hence the social calls function as contact calls. It remains unknown if social calls are used for recognition of roostmates of brown long-eared bats, the important factor in socially stable groups, though this hypothesis remains plausible (Bradbury and Vehrencamp 2011). We used playback experiments to demonstrate that brown long-eared bats responded to both social and echolocation calls of conspecifics. The statistically significant response involved investigation of the speakers broadcasting social stimuli, and higher emission of social calls around those speakers. There were also significantly larger number of echolocation calls recorded at the social call speaker. We assume that the last kind of activity is not the response per se, but it was related to the investigation flights and may confirm the reaction of bats to broadcasted sounds. We believe that bats' reaction occurred, because the playback with a fixed order of longer stimulus and shorter control phases was individually designed to reflect the specific behavior of the brown long-eared bat. No response of bats during pilot study, when the stimuli presentation was too short, showed that playback experiments should be adapted to the behavior of the focal species.

Most of the studies on contact calls in vespertilionid bats used only investigations and passes as responses to played back vocal stimuli (e.g. Ruczyński et al. 2007, 2009; Schöner et al. 2010; Arnold and Wilkinson 2011). Our study is one of the few that showed bat response with social calls. If the bats would only approach the speakers broadcasting the calls without emitting social calls, this would indicate that bats eavesdrop on and check the sound to locate roosts. Several species of temperate zone bats (noctules N. noctula, Daubenton's bats Myotis daubentonii, Natterer's bats, and Bechstein's bats Myotis bechsteinii) use echolocation and social calls to locate potential roosts, approaching the source of the sound of conspecifics (Ruczyński et al. 2007, 2009; Schöner et al. 2010; Furmankiewicz et al. 2011). Noctules, Bechstein's bats, and Natterer's bats are known to form fission-fusion colonies and frequently switch tree hollow roosts (Kerth 2008; Zeus et al. 2017, Furmankiewicz, unpublished). Roost switching may promote using calls for effective location of roosts containing roost mates

Table 1 Coefficients (and their 95\% confidence intervals) of binomial GL(M)Ms explaining variation in reaction of bats to playback experiments $(0=$ null reaction $)$

\begin{tabular}{|c|c|c|c|c|}
\hline \multirow[t]{2}{*}{ Term } & \multicolumn{4}{|l|}{ Response variable } \\
\hline & Passes & Inspection flights* & Echolocation sequences & Social calls \\
\hline Intercept & $0.339(-0.908,1.660)$ & $-1.609(-3.482,-0.276)$ & $0.087(-1.720,1.942)$ & $\begin{array}{l}-1.183(-3.128 \\
0.439)\end{array}$ \\
\hline $\begin{array}{l}\text { Phase of experiment (control v. } \\
\text { stimulus) }\end{array}$ & $-1.048(-2.830,0.592)$ & $1.946(0.168,4.103)$ & $-0.408(-2.275,1.375)$ & $2.521(0.617,4.881)$ \\
\hline $\begin{array}{l}\text { Type of stimulus (echolocation } \\
\text { v. social calls) }\end{array}$ & $-0.343(-2.019,1.288)$ & -16.957 & $-2.736(-5.939,-0.525)$ & $\begin{array}{l}-0.562(-2.847 \\
1.532)\end{array}$ \\
\hline Phase: Type & $2.164(-0.207,4.730)$ & 18.230 & $5.929(2.575,10.466)$ & $0.562(-2.320,3.555)$ \\
\hline ID of colony (random intercept) & $0.7875(0.000,1.630)$ & $<10^{-5}$ & $0.917(0.000,3.007)$ & $0.788(0.0002 .627)$ \\
\hline
\end{tabular}

Statistically significant $(P<0.05)$ beta coefficients are in bold; see Fig. 2 for descriptive statistics.

ID of colony was entered as a random factor (in the model of inspection flights it explained a negligible amount of variance and was dropped, see "Materials and methods" section).

*There was $100 \%$ nulls in the control phase of test for reaction on social calls (Fig. 2), which in the binomial GLM resulted in odds ratios near 0 and unknown confidence intervals for some model terms 
by these species. In contrast, colony members of the brown long-eared bat are faithful to attic roosts and to their colony within the same season and over many years (Entwistle et al. 2000; Burland et al. 2006; Furmankiewicz 2016). Tree-dwelling colonies switch roosts more frequently, but they seem to maintain stability of the social group, because bats form small stable colonies that do not frequently form subgroups (Entwistle et al. 2000; Heise and Schmidt 1988; Fleischmann and Kerth 2014; Zeus et al. 2017). Such behaviour does not require location of roosts containing conspecifics, because the roost is always the same or because the group is stable and stay together. In a field experiment with a conflict of interests among colony members about where to roost, brown long-eared bats always achieved a colony-wide consensus about communal roosts (Fleischmann and Kerth 2014). Those data suggest low degrees of fission-fusion behaviour in this species (Fleischmann and Kerth 2014) and no need for frequent recruitment of colony members to the roost, because colony members typically return to the same roosts or the same group every morning. Therefore contact calls in in this species are not used primarily to find roosts containing conspecifics. The investigations of the speakers and emission of social calls by bats during playback of social and echolocation calls suggests that brown long-eared bats use the social calls as contact calls to communicate with conspecifics and maintain associations with them.

Contact calls are adaptive in socially stable groups to maintain associations with roostmates. This requires roostmate recognition and the social calls of echolocating bats are well adapted to this function, because they can encode information about a bat's identity (Beecher 1989; Arnold and Wilkinson 2011; Bradbury and Vehrencamp 2011).

Social calls are emitted by roostmates of the brown longeared bat on returns to and emergence from roosts (Furmankiewicz 2016). These vocalisations are similar to the calling behavior described so far in only two other vespertilionid bats, pallid bats (Arnold and Wilkinson 2011) and evening bats (Nycticeius humeralis) (Wilkinson 1992). Surprisingly, contact calls in other bat families have been not so often observed, and so far their production has been described in five species of phyllostomid bats (Wilkinson and Boughman 1998; Carter et al. 2009, 2012; Gillam et al. 2013) and one species in the family Thyropteridae (Chaverri et al. 2013). Pallid bats emit a loud, partially audible frequency-modulated social call while in flight when return from foraging and perform circular flights before entering a crevice roost. These calls may play a role in colony member recognition and for maintaining contact within roostmates (Arnold and Wilkinson 2011). In evening bats group mates depart in pairs from the roost and emit contact calls, and bats return, circle and subsequently depart accompanied by a group mate. Those calls probably recruit and coordinate foraging among group members (Wilkinson 1992; Wilkinson and Boughman
1998). In brown long-eared bats about 30-40\% of individuals emerged or returned in pairs or sometimes in groups of 3-5 individuals (Furmankiewicz 2016), so the accompanying vocalisations may be used to maintain contact with conspecifics, or to affiliate socially with other colony members, that leave or return to feeding sites together. In the latter case calling behaviour on return to the colony may be a specific greeting behaviour. Greeting ceremonies are observed in many primate species, some canids, elephants, horses, dolphins, and parrots during fusions of social groups and involve recognition, approach and expression of mutual affiliation, reassurance and assessment of individuals (Bradbury and Vehrencamp 2011). Some of these species use complex vocal exchanges for these purposes. For example killer whales and dolphins respond to calls of conpecifics (Janik 2000; Miller et al. 2004). Advertisement and identification of one's identity is crucial for interindividual interactions in social species (Bradbury and Vehrencamp 2011) and may also occur without vocal exchange (Rendall et al. 2000). This is relevant to the results of our playback experiment. We recorded emission of social calls by brown long-eared bats in response to broadcasted echolocation calls of conspecifics. So, we do not confirm our hypothesis that higher-pitched echolocation calls are less important than social calls during bat communication, because of their more rapid attenuation in the air (Lawrence and Simmons 1981; Fenton 2003). We suggest that individuals arriving at the colony, or hearing the echolocation calls, as well as social calls, of conspecifics may fly up to other individuals and call with social calls, advertise themselves and await responses from the receiver as a greeting behaviour and reaffirmation of the receiver's identity. However, this idea needs further study.

Brown long-eared bat forms small maternity colonies in summer roosts. The colonies are socially stable and composed of about philopatric 10-30 individuals of both females and males (Furmankiewicz 2016). They split for the night for foraging and join again in the day roosts that are stable over the season. Bats emit loud social calls on arrivals to the roosts. Because they come back to the same group and same roost the calling behavior is not necessary to find roostmates in the roost, as is observed in fission-fusion societies. Bats benefit from living in social group because of social thermoregulation and information transfer (Kerth 2008; Krebs and Davies 2012; Russo et al. 2017). The requisite of social living is the ability to recognize and affiliate social bonds with roostmates. The recognition and affiliation processes in brown long-eared bat can be mediated by social calls that may function in this species as contact calls to maintain associations between roostmates. Further studies are needed to determine the mechanism underpinning this communication and to determine if individual recognition is possible via individual (or roost-specific) call signatures as would be required for roostmate recognition. 
Acknowledgements We are grateful to our students who helped us with fieldwork: Artur Maryjowski, Anna Czapla, Ewelina Siudut, Jacek Stefaniak, Zuzanna Hałat and Adam Nowakowski. We thank Konrad Hałupka for help with statistical analysis, and Paweł Federowicz, who made the amplifiers and speakers. We also are very grateful the reviewers for all critical and valuable comments.

Funding The study was funded by a grant from the Polish Ministry of Science and Higher Education (nr N304 080 32/3087) and the Institute of Zoology, University of Wrocław, Poland.

Availability of data and materials (data transparency) The video and sound recordings sampled in the field and datasets generated during the analysis are available from the corresponding author on reasonable request.

\section{Declarations}

Conflict of interest The authors have declared that no competing interests exist.

Ethical approval The ethical approval was not required for this study, because we did not use any invasive method that could harm or disturb animals.

Consent for publication We agree for publication of our manuscript in the Mammalian Biology.

Open Access This article is licensed under a Creative Commons Attribution 4.0 International License, which permits use, sharing, adaptation, distribution and reproduction in any medium or format, as long as you give appropriate credit to the original author(s) and the source, provide a link to the Creative Commons licence, and indicate if changes were made. The images or other third party material in this article are included in the article's Creative Commons licence, unless indicated otherwise in a credit line to the material. If material is not included in the article's Creative Commons licence and your intended use is not permitted by statutory regulation or exceeds the permitted use, you will need to obtain permission directly from the copyright holder. To view a copy of this licence, visit http://creativecommons.org/licenses/by/4.0/.

\section{References}

Ahlén I (1981) Identification of Scandinavian Bats by their sounds. Swedish University of Agriculture Sciences, Department of Wildlife Ecology. Report 6, Uppsala

Altringham JD, Fenton B (2003) Sensory Ecology and Communication in the Chiroptera. In: Kunz TH, Fenton MB (eds) Bat ecology. The University of Chicago Press, Chicago and London, pp 90-127

Arnold BD, Wilkinson GS (2011) Individual specific contact calls of pallid bats (Antrozous pallidus) attract conspecifics at roosting sites. Beh Ecol Soc 65:1581-1593. https://doi.org/10.1007/ s00265-011-1168-4

Balcombe JP, Fenton MB (1988) Eavesdropping by bats: the influence of echolocation call design and foraging strategy. Ethology 79:158-166. https://doi.org/10.1111/j.1439-0310.1988.tb00708.x

Barataud M (1996) The Inaudible World \& The World of Bats. Acoustic Identification of French Bats. Sittelle Publisher, Mens
Barataud M (2015) Acoustic Ecology of European Bats. Species Identification, Study of their Habitats and Foraging Behaviour. Biotope, Mèze; Muséum national d'Histoire naturelle, Paris

Barclay RMR (1982) Interindividual use of echolocation calls: eavesdropping by bats. Behav Ecol Sociobiol 10:271-275

Barr DJ, Levy R, Scheepers C, Tily HJ (2013) Random effects structure for confirmatory hypothesis testing: keep it maximal. J Mem Lang 68:255-278. https://doi.org/10.1016/j.jml.2012.11.001

Bates D, Maechler M, Bolker B, Walker S (2015) Fitting linear mixedeffects models using lme4. J Stat Softw 67(1):1-48. https://doi. org/10.18637/jss.v067.i01

Beecher MD (1989) Signaling systems for individual recognition-an information-theory approach. Anim Behav 38:248-261

Bolker BM, Brooks ME, Clark CJ, Geange SW, Poulsen JR, Stevens MHH, White J-SS (2009) Generalized linear mixed models: a practical guide for ecology and evolution. Trends Ecol Evol 24:127-135. https://doi.org/10.1016/j.tree.2008.10.008

Bradbury JW, Vehrencamp SL (2011) Principles of Animal Communication. Sinauer Associated, Sunderland

Burland TM, Entwistle AC, Racey PA (2006) Social and population structure in the brown long-eared bat Plecotus auritus. In: Zubaid A, McCracken GF, Kunz TH (eds) Functional and Evolutionary Ecology of Bats. Oxford University Press, New York, pp 185-198

Carter GG, Fenton MB, Faure PA (2009) White-winged vampire bats (Diaemus youngi) exchange contact calls. Can J Zool 87:604-608. https://doi.org/10.1139/Z09-051

Carter GC, Logsdon R, Arnold BD, Menchaca A, Medellin RA (2012) Adult vampire bats produce contact calls when isolated: acoustic variation by species, population, colony, and individual. PLoS ONE 7(6): 38791

Chaverri G, Gillam EH, Kunz TH (2013) A call-and-response system facilitates group cohesion among disc-winged bats. Behav Ecol 24(2):481-487. https://doi.org/10.1093/beheco/ars188

Chaverri G, Ancillotto L, Russo D (2018) Social communication in bats. Biol Rev 93:1938-1954

Christensen RHB, Hansen MK (2014) binomTools: Performing diagnostics on binomial regression models. $\mathrm{R}$ package version 1.0-2/ r33. https://R-Forge.R-project.org/projects/binomtools/

Coles RB, Guppy A, Anderson ME, Schlegel P (1989) Frequency sensitivity and directional hearing in the gleaning bat, Plecotus auritus (Linnaeus 1758). J Comp Physiol A 165(2):269-280

Cvikel N, Egert Berg K, Levin E, Hurme E, Borissov I, Boonman A, Amichai E, Yovel Y (2015) Bats aggregate to improve prey search but might be impaired when their density becomes too high. Curr Biol 25:206-211. https://doi.org/10.1016/j.cub.2014.11.010

Dechmann DKN, Heucke SL, Giuggioli L, Safi K, Voigt CC, Wikelski M (2009) Experimental evidence for group hunting via eavesdropping in echolocating bats. Proc Roy Soc Lond B Bio 276:27212728. https://doi.org/10.1098/rspb.2009.0473

Dechmann DKN, Wikelski M, van Noordwijk HJ, Voigt CC, VoigtHeucke SL (2013) Metabolic costs of bat echolocation in an nonforaging context support a role in communication. Front Physiol 4:66. https://doi.org/10.3389/fphys.2013.00066

Entwistle AC, Racey PA, Speakman JR (1996) Habitat exploitation by a gleaning bat, Plecotus auritus. Philos T Roy Soc B 351:921931. https://doi.org/10.1098/rstb.1996.0085

Entwistle AC, Racey PA, Speakman JR (2000) Social and population structure of a gleaning bat, Plecotus auritus. J Zool 252:11-17. https://doi.org/10.1111/j.1469-7998.2000.tb00815.x

Fenton MB (1970) A technique for monitoring bat activity with results obtained from different environments in southern Ontario. Can J Zool 48(4):847-851. https://doi.org/10.1139/z70-148

Fenton MB (2003) Eavesdropping on the echolocation and social calls of bats. Mamm Rev 33:193-204. https://doi.org/10.1046/j.13652907.2003.00019.x 
Fichtel C, Manser M (2010) Vocal Communication in Social Groups. In: Kappeler P (ed) Animal behaviour: evolution and mechanisms. Springer-Verlag, Berlin, Heidelberg, pp 31-54

Fleischmann D, Kerth G (2014) Roosting behavior and group decision making in 2 syntopic bat species with fission-fusion societies. Behav Ecol 25(5):1240-1247. https://doi.org/10.1093/beheco/ aru117

Furmankiewicz J (2004) Social calls and vocal activity of the Plecotus auritus in SW Poland. Le Rhinolophe 17:101-120

Furmankiewicz J (2008) Population size, catchment area and sex-influenced differences in autumn and spring swarming of the brown long-eared bat Plecotus auritus. Can J Zool 86:207-216

Furmankiewicz J (2016) The social organization and behavior of the brown long-eared bat Plecotus auritus. In: Ortega J (ed) Sociality in Bats. Springer International Publishing, Switzerland, pp 11-46. https://doi.org/10.1007/978-3-319-38953-0_2

Furmankiewicz J, Ruczyński I, Urban R, Jones G (2011) Social calls provide the tree-dwelling bats with an information about location of conspecifics at roost. Ethology 117(6):480-489. https://doi.org/ 10.1111/j.1439-0310.2011.01897.x

Gillam EH (2007) Eavesdropping by bats on the feeding buzzes of conspecifics. Can J Zool 85:795-801. https://doi.org/10.1139/ Z07-060

Gillam EH, Fenton MB (2016) Roles of acoustic social communication in the lives of bats. In: Fenton MB, Grinnel AD, Popper AN, Fay RR (eds) Bat Bioacoustics. The ASA Press and Springer, New York, pp 117-139

Gillam EH, Chaverri G, Montero K, Sagot M (2013) Social calls produced within and near the roost in two species of tent-making bats, Dermanura watsoni and Ectophylla alba. PLoS ONE 8(4):e61731. https://doi.org/10.1371/journal.pone.0061731

Hartig F (2020) DHARMa: Residual diagnostics for Hierarchical (Multi-Level/Mixed) Regression Models. R package ver. 0.3.3.0. http://florianhartig.github.io/DHARMa/

Heise G, Schmidt A (1988) Beträge zur sozialen Organisation und Ökologie des Braunes Langohres (Plecotus auritus). Nyctalus (n.f.) 2:445-465

Janik VM (2000) Whistle matching in wild bottlenose dolphins (Tursiops truncatus). Science 289:1355-1357. https://doi.org/10.1126/ science.289.5483.1355

Kerth G (2008) Causes and consequences of sociality in bats. Bioscience 58(8):737-746. https://doi.org/10.1641/B580810

Kondo N, Watanabe S (2009) Contact calls: information and social function. Jpn Psychol Res 51(3):197-208. https://doi.org/10. 1111/j.1468-5884.2009.00399.x

Krebs JR, Davies NB, West SA (2012) An Introduction to Behavioural Ecology. Wiley-Blackwell, Chichester

Kunz TH, Betke M, Hristov NI, Vonhof MJ (2009) Methods of assessing colony size, population size, and relative abundance of bats. In: Kunz TH, Parsons S (eds) Ecological and Behavioral Methods for the Study of Bats, 2nd edn. Johns Hopkins University Press, Baltimore, pp 133-157

Lawrence BD, Simmons JA (1981) Measurements of atmospheric attenuation at ultrasonic frequencies and the significance for echolocation by bats. J Acous Soc Am 71:582-590

Marler P (2004) Bird calls: a cornucopia for communication. In: Marler $\mathrm{P}$, Slabbekoorn H (eds) Nature's Music. The Science of Birdsong. Elsevier Academic Press, London, pp 132-177

Miller PJO, Shapiro AD, Tyack PL, Solow AR (2004) Call-type matching in vocal exchanges of free-ranging resident killer whales,
Orcinus orca. Anim Behav 67:1099-1107. https://doi.org/10. 1016/j.anbehav.2003.06.017

Möhres F (1967) Communicative characters of sonar signals in bats. In: Busnel R-G (ed), Animal Sonar Systems: Biology and bionics. Tome II Jouy-en-Josas: Laboratoire de Physiologie Acoustique, pp 939-945

Murphy SE (2012) Function of social calls in Plecotus auritus. PhD thesis, School of Life Sciences, University of Sussex

O'Shea TJ, Vaughan TA (1977) Nocturnal and seasonal activities of the pallid bat, Antrozous pallidus. J Mammal 58(3):269-284. https:// doi.org/10.2307/1379326

R Core Team (2020). R: A language and environment for statistical computing. R Foundation for Statistical Computing, Vienna. https://www.R-project.org/

Rendall D, Cheney DL, Seyfarth RM (2000) Proximate factors mediating "contact" calls in adult female baboons (Papio cynocephalus ursinus) and their infants. J Comp Psychol 114:36-46

Ruczyński I, Kalko EKV, Siemers BM (2007) The sensory basis of roost finding in a forest bat, Nyctalus noctula. J Exp Biol 210:3607-3615. https://doi.org/10.1242/jeb.009837

Ruczyński I, Kalko EKV, Siemers BM (2009) Calls in the forest: a comparative approach to how bats find tree cavities. Ethology 115:167-177. https://doi.org/10.1111/j.1439-0310.2008.01599.x

Russo D, Cistrone L, Budinski I, Console G, Della Corte M, Milighetti C, Di Salvo I, Nardone V, Brigham RM, Ancillotto L (2017) Sociality influences thermoregulation and roost switching in a forest bat using ephemeral roosts. Ecol Evol 7(14):5310-5321. https:// doi.org/10.1002/ece3.3111

Schöner CR, Schöner MG, Kerth G (2010) Similar is not the same: Social calls of conspecifics are more effective in attracting wild bats to day roost than those of other bat species. Behav Ecol Sociobiol 64(12):2053-2063. https://doi.org/10.1007/ s00265-010-1019-8

Swift SM (1998) Long-eared Bats. T\&AD Poyser Natural History, London

Vaughan TA, O'Shea TJ (1976) Roosting ecology of pallid bat Antrozous pallidus. J Mammal 57(1):19-42. https://doi.org/10.2307/ 1379510

Ward AJW, Webster M (2016) Mechanisms: Social Recognition and Social Organisation. In: Ward AJW, Webster M (eds) Sociality: The Behaviour of Group-Living Animals. Springer, Cham, pp 9-27. https://doi.org/10.1007/978-3-319-28585-6_2

Wilkinson GS (1992) Information transfer at evening bat colonies. Anim Behav 44:501-518. https://doi.org/10.1016/0003-3472(92) 90059-I

Wilkinson GS, Boughman JW (1998) Social calls coordinate foraging in greater spear-nosed bats. Anim Behav 55:337-350

Wilkinson GS, Carter G, Bohn KM, Caspers B, Chaverri G, Farine D, Günther L, Kerth G, Knörnschild M, Mayer F, Nagy M, Ortega J, Patriquin K (2019) Kinship, association and social complexity in bats. Behav Ecol Sociobiol 73:7

Zeus VM, Puechmaille SJ, Kerth G (2017) Conspecific and heterospecific social groups affect each other's resource use: a study on roost sharing among bat colonies. Anim Behav 123:329-338. https://doi.org/10.1016/j.anbehav.2016.11.015

Publisher's Note Springer Nature remains neutral with regard to jurisdictional claims in published maps and institutional affiliations. 